\title{
Front Matter: Volume 9015
}

, "Front Matter: Volume 9015," Proc. SPIE 9015, Color Imaging XIX: Displaying, Processing, Hardcopy, and Applications, 901501 (3 February 2014); doi: 10.1117/12.2052771

SPIE Event: IS\&T/SPIE Electronic Imaging, 2014, San Francisco, California, United SPIE. States 


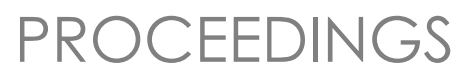

IS\&T / SPIE

Electronic

Imaging

SCIENCE AND TECHNOLOGY

\title{
Color Imaging XIX: \\ Displaying, Processing, \\ Hardcopy, and Applications
}

\author{
Reiner Eschbach \\ Gabriel G. Marcu \\ Alessandro Rizzi \\ Editors
}

3-5 February 2014

San Francisco, California, United States

Sponsored by

IS\&T-The Society for Imaging Science and Technology

SPIE

Published by

SPIE 
The papers included in this volume were part of the technical conference cited on the cover and title page. Papers were selected and subject to review by the editors and conference program committee. Some conference presentations may not be available for publication. The papers published in these proceedings reflect the work and thoughts of the authors and are published herein as submitted. The publishers are not responsible for the validity of the information or for any outcomes resulting from reliance thereon.

Please use the following format to cite material from this book:

Author(s), "Title of Paper," in Color Imaging XIX: Displaying, Processing, Hardcopy, and Applications, edited by Reiner Eschbach, Gabriel G. Marcu, Alessandro Rizzi, Proceedings of SPIEIS\&T Electronic Imaging, SPIE Vol. 9015. Article CID Number (2014)

ISSN: 0277-786X

ISBN: 9780819499325

\section{Copublished by}

\section{SPIE}

P.O. Box 10, Bellingham, Washington 98227-0010 USA

Telephone +1 3606763290 (Pacific Time) · Fax +1 3606471445

SPIE.org

and

IS\&T-The Society for Imaging Science and Technology

7003 Kilworth Lane, Springfield, Virginia, 22151 USA

Telephone +1 7036429090 (Eastern Time) · Fax +1 7036429094

imaging.org

Copyright @ 2014, Society of Photo-Optical Instrumentation Engineers and The Society for Imaging Science and Technology.

Copying of material in this book for internal or personal use, or for the internal or personal use of specific clients, beyond the fair use provisions granted by the U.S. Copyright Law is authorized by the publishers subject to payment of copying fees. The Transactional Reporting Service base fee for this volume is $\$ 18.00$ per article (or portion thereof), which should be paid directly to the Copyright Clearance Center (CCC), 222 Rosewood Drive, Danvers, MA 01923. Payment may also be made electronically through CCC Online at copyright.com. Other copying for republication, resale, advertising or promotion, or any form of systematic or multiple reproduction of any material in this book is prohibited except with permission in writing from the publisher. The CCC fee code is 0277-786X/14/\$18.00.

Printed in the United States of America.

Paper Numbering: Proceedings of SPIE follow an e-First publication model, with papers published first online and then in print and on CD-ROM. Papers are published as they are submitted and meet publication criteria. A unique, consistent, permanent citation identifier (CID) number is assigned to each article at the time of the first publication. Utilization of CIDs allows articles to be fully citable as soon as they are published online, and connects the same identifier to all online, print, and electronic versions of the publication. SPIE uses a six-digit CID article numbering system in which:

- The first four digits correspond to the SPIE volume number.

- The last two digits indicate publication order within the volume using a Base 36 numbering

system employing both numerals and letters. These two-number sets start with 00, 01, 02, 03, 04, $05,06,07,08,09,0 A, 0 B \ldots 0 Z$, followed by 10-1Z, 20-2Z, etc.

The CID Number appears on each page of the manuscript. The complete citation is used on the first page, and an abbreviated version on subsequent pages. Numbers in the index correspond to the last two digits of the six-digit CID Number. 


\section{Contents}

\section{vii Conference Committee}

ix Abstracts from "The Dark Side of Color" session
A. Rizzi, Univ. degli Studi di Milano (Italy); J. J. McCann, McCann Imaging (United States);
P. Urban, Fraunhofer-Institut für Graphische Datenverarbeitung (Germany); A. J. Woods,
Curtin Univ. (Australia); R. Eschbach, S. Morgana, Xerox Corp. (United States); A. Quaranta,
C. Bonanomi, Univ. degli Studi di Milano (Italy)

\section{SESSION 1 APPLIED COLOR AND PERCEPTION}

901502 Improving information perception from digital images for users with dichromatic color vision [9015-1]

O. Shayeghpour, D. Nyström, S. Gooran, Linköping Univ. (Sweden)

901503 Spectral analysis of omnidirectional color signals in natural scenes [9015-2]

S. Tominaga, D. Watanabe, K. Hirai, T. Horiuchi, Chiba Univ. (Japan)

901504 Realistic fetus skin color processing for ultrasound volume rendering [9015-3]

Y.-T. Kim, K. Kim, S.-C. Park, J. Kang, J.-H. Kim, Samsung Advanced Institute of Technology (Korea, Republic of)

901505 What impacts skin color in digital photos? [9015-4]

A. Lindner, S. Winkler, Advanced Digital Sciences Ctr. (Singapore)

\section{SESSION 2 MATERIAL COLORS: JOINT SESSION WITH CONFERENCES 9015 AND 9018}

901506 Microscale halftone color image analysis: perspective of spectral color prediction modeling [9015-5]

G. M. A. Rahaman, O. Norberg, P. Edström, Mid Sweden Univ. (Sweden)

901507 Reproducing the old masters: applying colour mixing and painting methodologies to inkjet printing [9015-6]

M. Olen, Univ. of the West of England (United Kingdom); J. Padfield, The National Gallery

(United Kingdom); C. Parraman, Univ. of the West of England (United Kingdom)

901508 Color prediction modeling for five-channel CMYLCLm printing [9015-7]

Y. Qu, P. Zitinski Elias, S. Gooran, Linköping Univ. (Sweden)

901509 Physical and optical dot gain: characterization and relation to dot shape and paper properties [9015-8]

M. Namedanian, D. Nyström, P. Zitinski Elias, S. Gooran, Linköping Univ. (Sweden) 
$90150 \mathrm{~A} \quad$ Gamut mapping in a high-dynamic-range color space [9015-9]

J. Preiss, Technische Univ. Darmstadt (Germany); M. D. Fairchild, J. A. Ferwerda, Rochester Institute of Technology (United States); P. Urban, Fraunhofer Institute for Computer Graphics Research (Germany)

9015 OB Color preservation for tone reproduction and image enhancement [9015-10]

C. Hsin, Z. W. Lee, Z. Z. Lee, S.-J. Shin, Feng Chia Univ. (Taiwan)

$90150 \mathrm{C}$ Color signal encoding for high dynamic range and wide color gamut based on human perception [9015-11]

M. Nezamabadi, S. Miller, S. Daly, R. Atkins, Dolby Labs. (United States)

\section{SESSION 4 PROCESSING}

9015 OD Design for implementation of color image processing algorithms [9015-12]

J. Whitesell, D. Patru, E. Saber, Rochester Institute of Technology (United States);

G. Roylance, B. Larson, Hewlett-Packard Co. (United States)

9015 OE Dynamic histogram equalization based on gray level labeling [9015-14]

B. Kim, G. Y. Gim, H. J. Park, Samsung Electronics Co., Ltd. (Korea, Republic of)

9015 OF Slide localization in video sequence by using a rapid and suitable segmentation in marginal space [9015-15]

S. Rajgure, V. Oria, New Jersey Institute of Technology (United States); P. Gouton, Lab. LEll, Univ. de Bourgogne (France)

$90150 \mathrm{~S}$ SVM-based automatic scanned image classification with quick decision capability [9015-16]

C. Lu, Purdue Univ. (United States); J. Wagner, B. Pitta, D. Larson, Hewlett-Packard Co.

(United States); J. Allebach, Purdue Univ. (United States)

\section{SESSION 5 CAMERAS AND DISPLAYS}

$9015 \mathrm{OH} \quad$ Optimal color temperature adjustment for mobile devices under varying illuminants [9015-17]

K. Choi, H.-J. Suk, KAIST (Korea, Republic of)

9015 Ol Primary selection for uniform display response [9015-18]

C. E. Rodríguez-Pardo, G. Sharma, Univ. of Rochester (United States); X.-F. Feng, Sharp Labs. of America, Inc. (United States)

$90150 \mathrm{~J} \quad$ Moire reduction using inflection point in frequency domain [9015-19]

D.-C. Kim, W.-J. Kyung, B.-S. Choi, Y.-H. Ha, Kyungpook National Univ. (Korea, Republic of)

9015 OK Recalling white point of smartphone under varying illuminants [9015-20]

K. Choi, J. Jang, H.-J. Suk, KAIST (Korea, Republic of) 
$9015 \mathrm{OL} \quad$ Evaluation of static color breakup for natual images on field sequential displays [9015-21] J. U. Kim, C. M. Yang, J. H. Bae, C.-W. Kim, Inha Univ. (Korea, Republic of); H.-S. Lee, D. Kim, Samsung Electronics (Korea, Republic of)

$90150 \mathrm{M} \quad$ Preserving color fidelity for display devices using scalable memory compression architecture for text, graphics, and video [9015-22]

F. Lebowsky, M. Nicolas, STMicroelectronics (France)

$90150 \mathrm{~N} \quad$ Simplifying irradiance independent color calibration [9015-23]

P. Bastani, B. Funt, Simon Fraser Univ. (Canada)

901500 Using statistical analysis and artificial intelligence tools for automatic assessment of video sequences [9015-24]

B. Ekobo Akoa, E. Simeu, TIMA Lab. (France); F. Lebowsky, STMicroelectronics (France)

\section{SESSION $6 \quad$ PRINTING AND HALFTONING}

9015 OP Hybrid halftoning using direct multi-bit search (DMS) screen algorithm [9015-25]

K. Chandu, M. Stanich, Ricoh Production Print Solutions, LLC (United States); C. W. Wu, B. Trager, IBM Thomas J. Watson Research Ctr. (United States)

$90150 Q \quad$ A Riesz energy based approach to generating dispersed dot patterns for halftoning applications [9015-26]

C. W. Wu, B. Trager, IBM Thomas J. Watson Research Ctr. (United States); K. Chandu, M. Stanich, Ricoh Production Print Solutions, LLC (United States)

9015 OR Yule-Nielsen effect in halftone prints: graphical analysis method and improvement of the Yule-Nielsen transform [9015-27]

M. Hébert, Lab. Hubert Curien, CNRS (France) and Institut d'Optique (France)

9015 OS Irregular clustered-dot periodic halftone screen design [9015-28]

C. Tang, Purdue Univ. (United States); A. Veis, Hewlett-Packard Scitex, Ltd. (Israel);

R. Ulichney, Hewlett-Packard Labs. (United States); J. Allebach, Purdue Univ. (United States)

9015 OT Effect of image capture device on the accuracy of black-box printer models [9015-29] J. Youn, J. Sun, Y. Ju, Purdue Univ. (United States); T. Kashti, T. Frank, D. Kella, HewlettPackard Indigo Ltd. (Israel); M. Fischer, Hewlett-Packard Labs. Israel Ltd. (Israel); R. Ulichney, Hewlett-Packard Labs. (United States); G. Adams, Hewlett-Packard Labs. (United Kingdom); J. Allebach, Purdue Univ. (United States)

9015 OU Ink-constrained halftoning with application to QR codes [9015-30] M. Bayeh, Univ. of Regina (Canada); E. Compaan, Univ. of Illinois at Urbana-Champaign (United States); T. Lindsey, Univ. of Kansas (United States); N. Orlow, Univ. of Illinois at Urbana-Champaign (United States); S. Melczer, Simon Fraser Univ. (Canada); Z. Voller, lowa State Univ. (United States) 
$90150 \mathrm{~V}$ ColorChecker at the beach: dangers of sunburn and glare (Invited Paper) [9015-31] J. McCann, McCann Imaging (United States)

$90150 Z$ You can't rely on color, yet we all do 2.0 (presented at Electronic Imaging 2013 The Dark Side of Color session) [9015-900]

F. L. van Nes, ErgoNes (Netherlands) and Technische Univ. Eindhoven (Netherlands)

Author Index

vi 


\section{Conference Committee}

Symposium Chair

Sergio R. Goma, Qualcomm Inc. (United States)

Symposium Cochair

Sheila S. Hemami, Northeastern University (United States)

Conference Chairs

Reiner Eschbach, Xerox Corporation (United States)

Gabriel G. Marcu, Apple Inc. (United States)

Alessandro Rizzi, Università degli Studi di Milano (Italy)

Conference Program Committee

Jan P. Allebach, Purdue University (United States)

Scott J. Daly, Dolby Laboratories, Inc. (United States)

Phil J. Green, Gjøvik University College (Norway)

Roger D. Hersch, Ecole Polytechnique Fédérale de Lausanne

(Switzerland)

Choon-Woo Kim, Inha University (Korea, Republic of)

Michael A. Kriss, MAK Consultants (United States)

Fritz Lebowsky, STMicroelectronics (France)

Nathan Moroney, Hewlett-Packard Laboratories (United States)

Carinna E. Parraman, University of the West of England (United Kingdom)

Shoji Tominaga, Chiba University (Japan)

Stephen Westland, University of Leeds (United Kingdom)

Session Chairs

1 Applied Color and Perception

Reiner Eschbach, Xerox Corporation (United States)

2 Material Colors: Joint Session with Conferences 9015 and 9018

Maria V. Ortiz Segovia, Océ Print Logic Technologies (France)

Jon Yngve Hardeberg, Gjøvik University College (Norway)

3 High Dynamic Range

Alessandro Rizzi, Università degli Studi di Milano (Italy)

4 Processing

Fritz Lebowsky, STMicroelectronics (France) 
5 Cameras and Displays

Gabriel G. Marcu, Apple Inc. (United States)

Mahdi Nezamabadi, Dolby Laboratories (United States)

6 Printing and Halftoning

Carinna E. Parraman, University of the West of England (United Kingdom)

7 The Dark Side of Color

Reiner Eschbach, Xerox Corporation (United States) 


\title{
The dark side of color VI
}

\author{
Alessandro Rizzi ${ }^{\mathrm{a}}$, John J. McCann ${ }^{\mathrm{b}}$, Philipp Urban ${ }^{\mathrm{c}}$, Andrew J. Woods ${ }^{\mathrm{d}}$, Reiner Eschbach ${ }^{\mathrm{e}}$, Stephen \\ Morgana $^{\mathrm{e}}$, Anna Quaranta ${ }^{\mathrm{a}}$, Cristian Bonanomi ${ }^{\mathrm{a}}$ \\ ${ }^{a}$ Dept. of Computer Science - Università degli Studi di Milano, Italy \\ ${ }^{\mathrm{b}}$ McCann Imaging, USA \\ ${ }^{\mathrm{c}}$ Fraunhofer-Institut für Graphische Datenverarbeitung, Germany \\ ${ }^{\mathrm{d}}$ Curtin University, Australia \\ ${ }^{\mathrm{e}}$ Xerox Corp., USA
}

\begin{abstract}
This year, at Electronic Imaging 2014, as part of the "Color Imaging XIX: Displaying, Processing, Hardcopy, and Applications" and "Human Vision and Electronic Imaging XVIII" conferences, we hold the sixth annual special session entitled, "The Dark Side of Color". This session aims at introducing innovative thinking, opening discussion from experts working in a wide range of disciplines related with color, fostering ideas and stimulating ongoing issues and revealing common misunderstanding in color science and technology. It is comprised of a limited number of invited short presentations that are presented as summaries in this paper together with an overall description of the session point of view.
\end{abstract}

Keywords: Dark side of color, Color, Color models, Color teaching, Colorimetry, Vision, Color related phenomena

\section{WHAT THIS SESSION IS ABOUT}

Color is a very complex phenomenon that cannot sufficiently be explained using only simple physical principles. Instead, a more holistic approach incorporating the human vision system of eye and brain is needed to understand how the base physical stimuli are transformed into the visual colors we see.

Color related topics are often taught and communicated without presenting their inner complexity, their limits and the simplifications that generally are taken at some point. Dealing with color is usually reduced to the automatic and repetitive use of pre-defined "recipes" and this can lead to the risk of loosing the overall framework and consequently a correct understanding of the technique to use.

Classic colorimetric methods, specifically designed to deal with color in aperture mode (isolated, out of visual context), have become dominant in digital color science and technology. Their use has been extended to deal with a great variety of situations in which color is considered within a visual context, thus outside of its initial scope. As such, the aperture approach has been very successful in describing a vast number of color effects. However, in some cases, an extension of the aperture view seems problematic, since the context plays a major role. Color science is facing this transitional evolution in order to deal with color in context and appearance, but without substantial changes in their original foundation.

There is a need for widening the scientific debate and discuss about paradigms. This can be achieved by, for example, new questions, different attention for details; information in the margins that so far are often discounted or overlooked. These aspects are what we consider to be the "dark side of color".

The invited speakers of this session have been asked to stimulate ideas and discussions on the needs and the characteristics of possible alternative approaches and/or point of view. This session aims at suggesting paradigm shifts, lateral thinking and bottom up experimentation by re-addressing the current state of the evolving situation in color in sciences, arts and technologies. 
Following these principles, every speaker has chosen a topic of his/her preference and presents open issues and problems in a short 15-minutes presentation. The presentation abstracts are reported in the following paper to give the reader a glance on the discussed topics.

We would like to stress that basically no answers are expected to arise from the presentations of this session, but more likely questions and perspective shifts.

\section{THE SPEAKERS}

Here are the abstracts of the speakers that will participate at this Dark Side of Color session.

\section{1 "ColorChecker at the beach: dangers of sunburn and glare" John J. McCann, McCann Imaging (United States)}

In High-Dynamic-Range (HDR) imaging, optical veiling glare sets the limits of accurate scene information recorded by a camera. But, what happens at the beach? Here we have a Low-Dynamic-Range (LDR)scene with maximal glare. Can we calibrate a camera at the beach and not be burnt? We know that we need sunscreen and sunglasses, but what about our camera? The effect of veiling glare is scene-dependent, so when we compare RAW camera digits with spotmeter measurements we find significant differences. As well, these differences vary, depending on where we aim the camera. When we calibrate our camera at the beach we get data that is valid for only that part of that scene. Camera veiling glare is an issue in LDR scenes in uniform illumination with a shaded lens.

\section{2 "The bright future of metameric blacks" Philipp Urban, Fraunhofer-Institut für Graphische Datenverarbeitung (Germany)}

Reconstructing spectral reflectances from low-dimensional camera responses is an ill-posed problem addressed by many researchers so far. Independently from the reconstruction approach, estimated reflectances may always deviate from the ground truth by device metameric black spectra. What seems to be a drawback on the spectral acquisition side may be utilized to conceal device limitations in spectral printing in order to create copies matching with originals under selected illuminants. Such a strategy enables the use of perceptually meaningful distance metrics for mapping non-reproducible reflectances into the spectral gamut of the printer satisfying colorimetric criteria across a hierarchical set of considered illuminants. In the talk, I briefly explain this approach and show some examples of spectral prints.

The concept might be extended to reproduce optical material properties (defined by the Bidirectional Reflectance Distribution Function - BRDF) by novel multi-material 2,5D and 3D printers. Here, prints can be perceptually optimized with respect to a set of measuring geometries by picking in-gamut BRDFs deviating from given BRDFs only by metameric blacks. In this context, metameric blacks refer to the difference of BRDFs that match for the considered measuring geometries. The strict requirement of a perfect match might be relaxed by perceptual distance criteria. There are various open questions related to this BRDF gamut mapping strategy, such as "How to select meaningful measurement geometries for a BRDF considering the shape of a 3D-object?" or "What is the perceptual error for notconsidered geometries?" Furthermore, it is unclear so far, how to predict perceptual differences between materials for geometries where the radiance factor exceeds one (here the materials have lightness values larger than the lightness of the perfect reflecting diffuser).

\section{3 “Can Color Management and Anaglyph 3D Images be Friends Once More?" Andrew J. Woods, Curtin University, Perth (Australia)}

The anaglyph 3D method is a very widely used technique for presenting stereoscopic 3D images - particularly for printed 3D images, but also for emissive displays such as LCDs. Left and right images are encoded in two complimentary color channels (often red left, cyan right) and the observer wears a pair of 3D glasses containing appropriate color filters at the left and right eyes. One of the important characteristics when presenting stereoscopic 3D 
images is that the left and right image channels must be maintained separate. If any mixing or leakage occurs between the image channels, this will be interpreted as crosstalk or ghosting, and can significantly degrade 3D image quality if leakage levels are high.

Now let's consider color management - a process used to maintain color consistency or color accuracy between different display devices or display techniques. Color management involves the characterisation of the color properties of a display and the use of a color management engine to vary the color channel values using a mathematical formula to achieve a consistent appearance of color between displays. The use of color management is now a common feature in many computer operating systems, image processing software, and printers. The use of color management can result in very good color consistency between displays, however the process of varying the color channels also results in the mixing of color channels which is bad for the presentation of high-quality anaglyph 3D images.

On this basis, color management can adversely affect the quality of anaglyph 3D images, because color management mixes the color channels, and anaglyph 3D requires the color channels to be maintained separate. In essence, color management adds crosstalk to anaglyph 3D images.

The printing of anaglyph 3D images is particular badly affected by the effects of color management.

This paper raises a number of open ended questions about how color management and anaglyph 3D images can be friends once more.

Firstly, color management is now so tightly integrated with the computer operating system and printer drivers that it is near impossible to override color management, and to allow control the individual color channels directly. We need a way of bypassing color management in these scenarios.

Secondly, color management does have advantages and it would be beneficial if a color management algorithm could be implemented which does not introduce crosstalk into anaglyph 3D images. The author believes that this is possible to develop a colour management algorithm which does not cause crosstalk in anaglyph 3D images, but it remains an outstanding task to prove this possibility.

Can color management and anaglyph 3D images be friends once again?

\section{4 "Feeling edgy about color blindness" Reiner Eschbach, Stephen Morgana, Xerox Corp. (United States); Anna Quaranta, Cristian Bonanomi, Alessandro Rizzi, Università degli Studi di Milano (Italy)}

The classic explanation of color blindness is based on the lack or on a malfunctioning of channel sensors. This has led in some cases to simplified models of color-blind people visual perception: e.g. miss of "green" cones, lack of green visual component.

There is no doubt that the base of color blindness is a problem for some kind of cones, but recent findings suggest that color sensation could be based on low level mechanisms different from the elemental Von Helmoltz tri-chromacy ${ }^{1}$. Moreover, other less recent findings suggest an important role of edges and gradients in the formation of color sensation ${ }^{2}$.

The hypothesis here is that color blindness could be not just the absence or a diminished signal from the defective channel. The idea is that color-blind people compensate in some way using edges, considering that edges are the base of normal vision too.

Here we present a discussion based on a very preliminary tests about the role of edges in normal and color-blind vision.

\section{THE PREVIOUS DARK SIDE SESSIONS}

Here is a list of the speakers and topics that have participated at the previous Dark Side of Color sessions.

\subsection{The dark side of color I (2009)}

"Well asked questions" Reiner Eschbach

"Pictorial information as transcribed by the artist or designer" Stephen Hoskins

"Consider the Size: And Other Display Features" Garrett M. Johnson

“Adaptation! ... What Adaptation?” John McCann 
"The Opposite of Green is Purple?" Nathan Moroney

"Now...what color was that again?" Sabine Süsstrunk

"Stepford - the city for Colour Engineering" Stephen Westland

\subsection{The dark side of color II (2010)}

"Color naming: color scientists do it between Munsell Sheets of Color" Giordano Beretta and Nathan Moroney

"Size matters: The problem of color-difference estimation for small visual targets" Robert C. Carter and Louis D.

Silverstein

"Controlled versus uncontrolled viewing conditions in color evaluation" Reiner Eschbach

"Mind over Matter" Jennifer Gille

"Globalization of color" Paul Hubel

"The appearance of illusions and the delusion of reality" John McCann

\subsection{The dark side of color III (2011)}

"The Color Side of Dark" Raja Bala

"What a bad signal from this strange device!" Alessandro Rizzi

"HDR Imaging and Color Constancy: Two Sides of the Same Coin?" John McCann

"Is the future of digital printing paperless?" Giordano Beretta, Eric Hoarau, Jun Zeng

"Can less be more?" Jan Allebach

“Can displays go wild?" Gabriel Marcu

\subsection{The dark side of color IV (2012)}

"The dark side of CIELAB" by Gaurav Sharma and Carlos Eduardo Rodriguez-Pardo

"Complexitites of complex contrast" by Eliezer Peli

"It's not the pixel count, you fool" by Michael A. Kriss

"Color imaging and aesthetics: is there the cheshire cat?" by Elena A. Fedorovskaya

"Dark texture in artworks" by Carinna E. Parraman

"Harmonious colors: from alchemy to science" by Giordano B. Beretta, Nathan M. Moroney

\subsection{The dark side of color $V$ (2013)}

"Can trichromats really know what dichromats see?" Michael H. Brill, Datacolor (United States)

"Color scales for visualization: traveling though color space" Bernice E. Rogowitz, Visual Perspectives Consulting (United States)

"Color spaces" Jan J. Koenderink, Technische Univ. Delft (Netherlands)

"You can't rely on color, yet we all do" Floris L. van Nes, Technische Univ. Eindhoven (Netherlands)

"How 'high-level' is human color perception? Michael E. Rudd, Univ. of Washington (United States)

"Complex spatiochromatic interactions in a real world art laboratory" Scott Daly, Dolby Labs., Inc. (United States)

\section{REFERENCES}

1. H. Hofer, B. Singer, and D.R. Williams, Different sensations from cones with the same photopigment, J. of Vision (2005) 5, 444-454.

2. E.H. Land, J.J. McCann, Lightness and Retinex Theory, J Opt Soc Am, (1971) 61, 1-11. 